\title{
The Influence of Pre-Heating on the Weldability of Pure Copper by FSW
}

\author{
Pierpaolo Carlone ${ }^{*}$ and Gaetano S. Palazzo
}

Department of Industrial Engineering, University of Salerno, Via Ponte Don Melillo 1, 84084, Fisciano (SA), Italy

\begin{abstract}
This paper deals with an experimental investigation on the friction stir welding of pure copper. $4 \mathrm{~mm}$ thick copper plates have been welded in the butt joint configuration using a conical unthreaded tool, with and without preheating. An electrically heated backing plate has been employed to increase the initial temperature of the plates and to investigate the influence of pre-heating on the weld ability of the considered material. The welded joints have been analyzed by means of macroscopic and microscopic observations, microhardness measurements and tensile tests. Obtained outcomes suggest that more complex pin shape is needed to promote an adequate material flow without preheating.
\end{abstract}

Keywords: Copper, friction stir welding, microhardness, microstructure, pre-heating, tensile properties.

\section{INTRODUCTION}

Friction stir welding (FSW) is a solid-state welding process, developed and patented by The Welding Institute (TWI) of Cambridge in 1991. FSW has received a great deal of attention as a suitable alternative to fusion welding processes. If compared with conventional techniques, FSW provides remarkable advantages in terms of joint quality, microstructure and residual stresses. During the process a non-consumable rotating tool, constituted by a shoulder and a pin, is plunged between the adjoining edges of the parts to be welded and moved along the desired weld line. The heat generated by frictional effects and plastic deformation locally increases the work piece temperature. As a consequence, the softened material is forced to flow around the pin, from the front (leading edge) to the rear (trailing edge) according to complex patterns, resulting in a solid state weld $[1,2]$. Most of researchers support the similarity of the FSW with the extrusion process in proximity of the pin, assisted also by forging action played by the shoulder. This hypothesis is also supported by the formation of periodic band structure, namely onion rings, observed in some materials and whose spacing is strictly related to process parameters [2-4]. Moreover, several specific defects are also imputable to inadequate material flow and deposition, mainly related to unsuitable process parameters $[5,6]$. Even if the application of FSW to aluminum alloys has been widely investigated [2-7] and relevant issues have been clarified, for the effective employment of the technique to other engineering materials, in particular copper, several questions are still open. Indeed, despite the interesting and recently published reports [8-20], a systematic study is lacking. What is more, published results are often contrasting and a convergence of the scientific community on some issues, such as the characteristics of the different welding

*Address correspondence to this author at the Department of Industrial Engineering, University of Salerno, Via Ponte Don Melillo 1, 84084, Fisciano (SA), Italy; Tel: 0039089 964320; Fax: 0039089 964307;

E-mail: pcarlone@unisa.it zones and relationship between welding parameters, recrystallization phenomena, and microhardness, seems quite far, as outlined in the following brief literature analysis.

Sakthivel et al. successfully joined $2 \mathrm{~mm}$ thick copper sheet by FSW, using a rotational speed of $1000 \mathrm{rpm}$ and welding speed of $30 \mathrm{~mm} / \mathrm{min}$. A hardness increase in the stir or nugget zone (NZ) with respect to the base material (BM) was detected and attributed to the finer microstructure induced by dynamic recrystallization phenomena. Furthermore, the presence of a thermo-mechanical affected zone (TMAZ) and of onion ring patterns was clearly declared [12]. Sound joints ( $5 \mathrm{~mm}$ thick) were obtained by Xie et al. using a tool with cylindrical threaded pin [13]. A significant dependence of the recrystallized grain size and microhardness on the rotating speed was evidenced. In particular in the upper range of the considered rotational speeds $(600-800 \mathrm{rpm})$ a decrease of the microhardness with respect to the BM was found, despite the finer microstructure observed. An extensive experimental investigation was carried on by Sun et al. [14]; providing the process window for the FSW of $2 \mathrm{~mm}$ thick copper sheet as a function of rotating speed, welding speed, and applied load. Their outcomes support what already indicated in [13]. On the other hand, different findings were pointed out by Shen et al., whose experimental results evidence a non-linear relationship between welding parameters, recrystallized grain size and microhardness [15]. The influence of the heat input condition on the microstructure and mechanical properties in pure copper FSW was investigated by Xue et al. in [16]. Reported results highlight that reducing the heat input a finer grain size in the NZ, characterized by a lower density of twins, can be obtained. At the same time, an increase of microhardness and yield strength was found. An equiaxed grain structure in the NZ, surrounded by coarser grains in the heat affected zone (HAZ) without a distinct TMAZ was observed by Lee et al. [18]. Moreover the role of the dislocation density rather than of the grain size was declared as dominant to determine the microhardness in the stir zone. Two different tool geometries, characterized by a 
threaded and a square profile, were used by Khodaverdizadeh et al. to join $5 \mathrm{~mm}$ thick copper plates by FSW [17]. It was pointed out that the employment of the square pin induces a higher degree of plastic deformation, major temperature peak, a finer grain structure and better mechanical properties. A common point between the aforementioned reports is related to the relatively complex geometry of the pin tool. To authors' best knowledge, the application of simpler tool, characterized by unthreaded smooth pin, to copper FSW, has not been accurately explored. In this regard it should be considered that unthreaded tools are cheaper, more robust, and easier to renovate with respect to more complex geometries.

In this paper results provided by an experimental investigation on friction stir welding of pure copper are exposed and discussed. $4 \mathrm{~mm}$ thick copper plates have been welded in the butt joint configuration using a conical smooth pin tool. Several processing conditions have been reproduced, varying rotating and welding speed, as well as the initial temperature of the adjoining plates. An electrically heated backing plate has been designed and realized to investigate the influence of pre-heating on the welded material. Welded samples have been subjected to macroscopic and microscopic observation, to detect the presence of defects and analyze welding microstructures. The influence of process conditions on the microhardness distribution and tensile properties has also been investigated. The adopted methodologies and devices are reported in Section 2, while in Section 3 the obtained results are shown and discussed. Finally, Section 4 summarizes the relevant findings of the performed analysis.

\section{MATERIALS AND METHODS}

In the present study, C10100 pure copper plates, obtained by a rolling process followed by a finishing cold drawn operation, have been joined by FSW. The dimensions of each plate are: length $120 \mathrm{~mm}$, width $30 \mathrm{~mm}$, and thickness $4 \mathrm{~mm}$. Friction stir welds have been executed in the butt joint configuration, in parallel to the drawing direction using a machining center (MCX 600 ECO). Despite the intriguing advantages provided by the FSW process, in the case of copper welding one of the main drawbacks is related to some conditions to be satisfied to induce an opportune material flow. As already observed by Hwang et al., a suitable temperature range for a successful process is between $460^{\circ} \mathrm{C}$ and $530^{\circ} \mathrm{C}$ [11], which, considering the high thermal diffusivity of copper, requires a strong and concentrate heat input.

This requirement could be satisfied, for instance, regulating the heat input by increasing the rotating speed and reducing the welding speed. However, this strategy carries on evident negative implications on the productivity and on the final grain size $[13,14]$. It should be also considered that a global worsening of the microstructural features and of the mechanical properties is attributed to the increase of the heat input [16]. In the present investigation, the initial temperature of the adjoining material is uniformly increased by means of apre-heating step, performed using a steel clamping fixture, shown in Fig. (1a). The fixture has been opportunely designed to simultaneously heat the welding
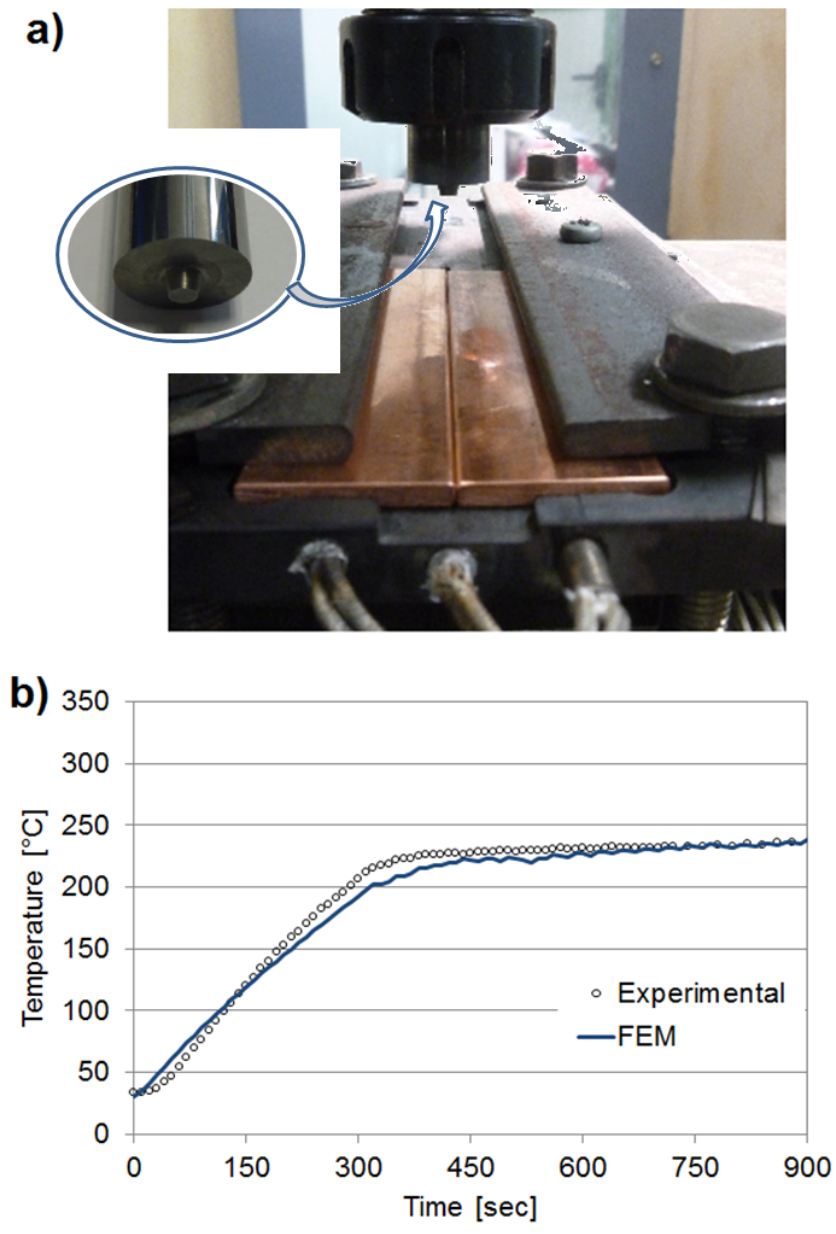

c)

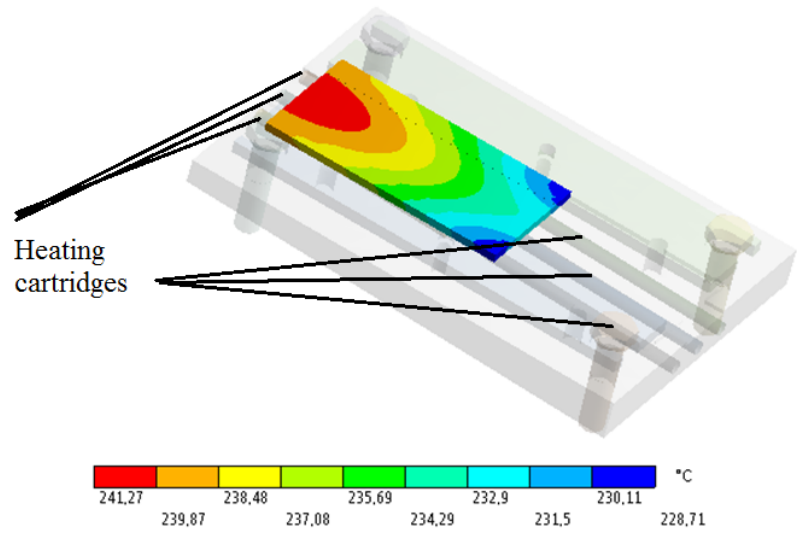

Fig. (1). Experimental set-up (a); comparison between numerical and experimental temperature profiles in the center of the plates (b); temperature distributions in the adjoining sheets at the end of the pre-heating step (c).

material (before the beginning of the welding) and fix the plates according to the desired tilt angle. Six high density cartridge heaters (Under Control Instruments LTD ${ }^{\circledR}$; length $100 \mathrm{~mm}$, diameter $6.5 \mathrm{~mm}$, nominal power $300 \mathrm{~W}$ ) have been embedded in holes drilled into the backing plate. A thermal graphite compound (Fischer Elektronik) has been applied to facilitate the insertion of the cartridge and improve the thermal matching with the plate. The heating system is controlled by a JUMO ecoTRON T thermostat 
connected with a thermocouple embedded in the backing plate in proximity of one of the heating cartridge.

The number and the position of the heating cartridges has been defined by means of a FEM thermal model, including the backing plate, the clamping system and the adjoining sheets, in order to obtain an uniform initial temperature distribution into the processing material. The adopted configuration is characterized by three heating elements on each side of the backing plate, with axis parallel to the weld line, as shown in Fig. (1a). In the same figure a picture showing the shoulder and the pin of the employed tool is included. The reliability of the thermal model has been tested comparing the temperature in the mid-length point between the adjoining edges, measured using a $\mathrm{K}$ type thermocouple, with the corresponding numerical profile, as reported in Fig. (1b). The good agreement found evidences the fair predictive capability of the model. From the same plot it should be noted that the processing material is interested by a consistent temperature increase in the first $300 \mathrm{sec}(5 \mathrm{~min})$ of heating, and then an asymptotic temperature of about $235^{\circ} \mathrm{C}$ is slowly approached. After $900 \mathrm{sec}(15 \mathrm{~min})$ of heating, an approximately uniform temperature distribution inside the adjoining plates is established, as depicted in Fig. (1c). In the same figure the position of the heating cartridges is indicated. Following the above result, a pre-heating time of $15 \mathrm{~min}$ has been adopted for each test employing the heating facility. The tool-work piece relative movement has been imposed after the pre-heating time.

The experimental plan has been designed considering three factors, namely the rotating speed $\omega$, the welding speed $v$ and the material pre-heating. In particular three levels for $\omega$ $(600,800$, and $1000 \mathrm{rpm})$, four levels for $v(50,100,150$, $200 \mathrm{~mm} / \mathrm{min}$ ), and two levels for the pre-heating facility (with and without) are defined, following literature indications and taking into account results provided by preliminary tests. A reduced design of experiments has been adopted, excluding the welding conditions suggesting a relatively lower probability of success, as depicted in Fig. (2). Other process parameters, namely the tilt angle $\Theta$ and the pin penetration $\mathrm{p}$, have been defined as $2^{\circ}$ and $0.1 \mathrm{~mm}$. As aforementioned, the tool was characterized by a conical unthreaded pin (height $3.80 \mathrm{~mm}$, major diameter $6.20 \mathrm{~mm}$, and cone angle $30^{\circ}$ ) and a $20 \mathrm{~mm}$ diameter shoulder, realized as a single piece in High Speed Steel. In what follows, welds executed with pre-heating are referred to as hot weld (HW), regardless of processing parameters. Otherwise, the term cold weld $(\mathrm{CW})$ is used.

Welded samples have been subjected to visual inspection and qualitative analysis of crowns and roots, to detect evident presence of flashes and other undesired features. Specimen have been then sectioned in correspondence of the half-length and then polished and lapped on a rotating plate using abrasive discs $(800,1200$, and 2500 grade), followed by a final polishing using a polycrystalline diamond suspension $(3 \mu \mathrm{m})$ on tissue disc. Chemical etching has been performed for 30 seconds at room temperature using a distilled water, ammonia and hydrogen peroxide $(3 \%)$ solution. The obtained samples have been subjected to low magnification (20x) microscopic analysis to individuate the presence of internal defect, such as tunnel defect, pin hole, and kissing bond. The grain size in the NZ has been measured using conventional metallographic procedures [17]. Vickers microhardness has been measured using a LEICA VMHT AUTO machine along three programmed linear patterns, orthogonal to the weldline. In particular, the first measurement line has been defined at the mid-thickness of the cut section of the sheet, while the other lines have been programmed at a distance equal to $1 \mathrm{~mm}$ from the top and bottom surface. The following parameters have been adopted: distance between two consecutive indentations 1 $\mathrm{mm}$, up to a maximum distance of $25 \mathrm{~mm}$ from the weld line towards the advancing and the retreating sides, indentation load $50 \mathrm{gf}(0.49 \mathrm{~N})$, loading time $15 \mathrm{sec}$, and indentation speed $60 \mu \mathrm{m} / \mathrm{sec}$. The mechanical properties of welded samples have been inferred by means of the conventional tensile test, using a MTS machine $(30 \mathrm{KN})$. A displacement controlled mode has been employed, adopting a constant traverse speed equal to $0.02 \mathrm{~mm} / \mathrm{sec}$ in each test. Three dogbone samples have been machined from the welded sheets, orthogonally to the weld line, for each processing condition. The width of each sample is $2 \mathrm{~mm}$, while the thickness is equal to the thickness of the welded sheets.

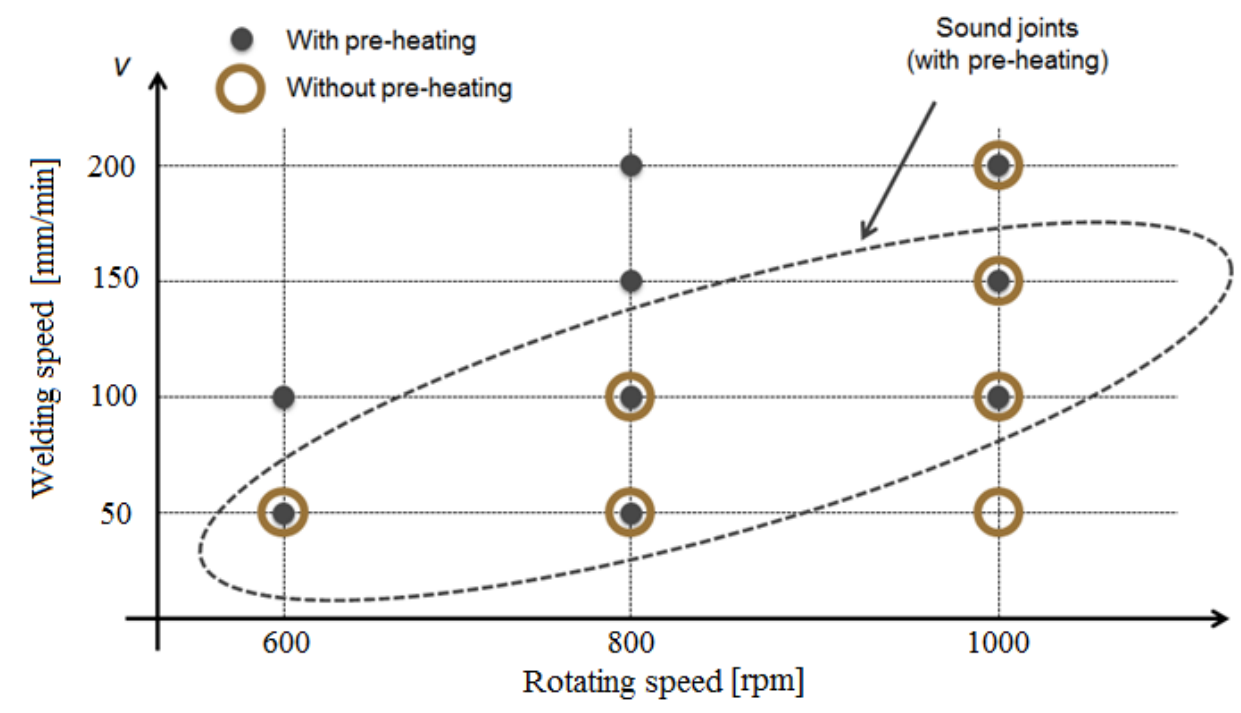

Fig. (2). Design of experiments. 


\section{RESULTS AND DISCUSSION}

Macroscopic pictures of some welded samples, obtained respectively without and with pre-heating, are shown in Fig. (3). As far as the crown aspect is regarded, it appears quite smooth and characterized by the presence of approximately circular marks in all CWs, suggesting a prevalence of sliding at the shoulder - work piece contact surface. Moreover, no relevant flashes have been observed. For all the considered values of $\omega$, however, welding defects

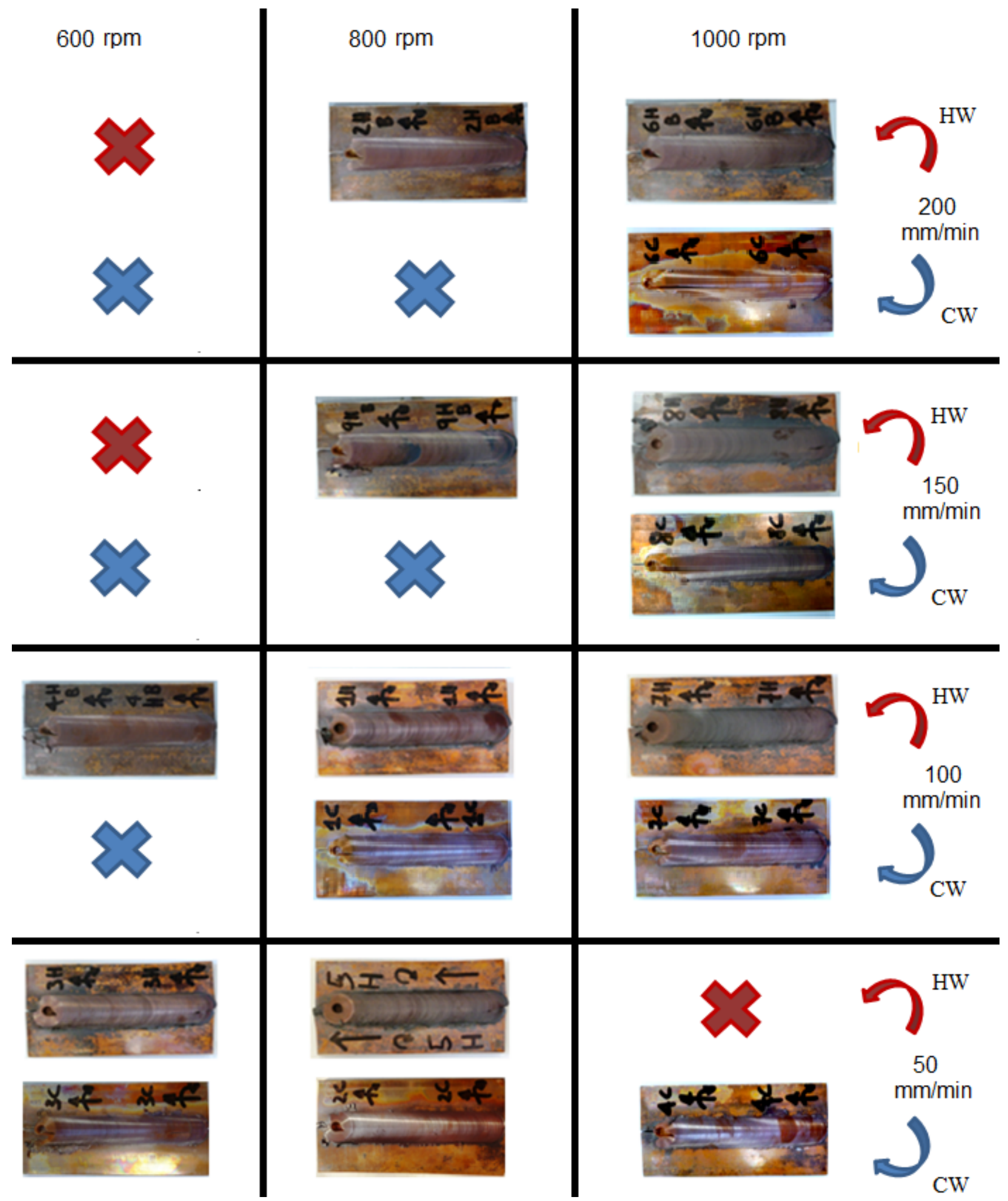

Fig. (3). Hot (HW) and cold (CW) welds. The "x" symbols refer to test cases excluded from the design of experiments. 
have been found at the beginning and the end of the welds. In particular, this feature becomes strongly pronounced for pitch $(v / \omega)$ values greater than $0.1 \mathrm{~mm} / \mathrm{rev}$. Relatively to HWs, a slightly rough surface, with a visible material deposition in correspondence of the advancing side, has been observed at lower $v$ for all $\omega$ values. As can be seen, the temperature increase, due to the electrical pre-heating, has promoted undesired reactions between processing material and air. As a consequence, HWs surfaces appear darker if compared with the corresponding CW surfaces. Obviously, this problem can be easily overcome using a shielding inert gas. Appreciable improvements have been achieved for pitch values greater than $0.15 \mathrm{~mm} / \mathrm{rev}$. The above effect is imputable to the unstable equilibrium condition between the material hardening due to plastic deformation (promoting sliding) and softening caused by heat dissipation (increasing sticking), implicitly confirming the dependence of the contact state on the process parameters.

The microscopic observation of the cross section of the joints has revealed the presence of internal tunnel defects localized in the lower region of the NZ towards the advancing side in all the samples welded without preheating, unregard of process parameters. Moreover, kissing bond defects have also been detected in some of the aforementioned test cases. On the other hand, sound joints have been obtained pre-heating the adjoining material in all the considered range of rotating speeds, but assuming limited values of $v$. A threshold (upper) limit of $0.15 \mathrm{~mm} / \mathrm{rev}$ for the pitch has been identified; tunnel defects have been found in all samples welded without satisfying this condition. Comparing the process window in Fig. (2) with results available in the previous literature, it is worth noting that the aforementioned limit is not active using tools characterized by relatively more complex (threaded or squared for instance) pin shape. As a consequence, it can be reasonably stated that, even if relatively cheaper and more robust, cylindrical smooth pin are not able to promote an adequate material stirring when processing copper.

The metallographic analysis of the cross section has not evidenced clear boundaries between FSW zones, in agreement with [18]. Indeed, even if a slight grain refinement has been observed in the central zone of the cross section, the initial microstructure was quite fine and comparable with the microstructure in the NZ. Equiaxed grains have been detected in the NZ of all welded samples, congruently with the influence of plastic deformation and heat input on recrystallized grain size. In particular a finer microstructure has been found in $\mathrm{CW}$ if compared with $\mathrm{HW}$ realized using the same parameters, as reported in Fig. (4a, b). This feature has been attributed to the relatively higher temperature experienced by the material in HW condition. Differently from FSW of some aluminum alloys, growth phenomena play a role comparable to dynamic recrystallization phenomena, justifying the use of additional rapid cooling [20] to induce an ultra-fine microstructure.

An intriguing aspect highlighted in Fig. (4a, $\mathbf{b})$ is related to the non-linear relationship between the welding speed and the recrystallized grain size measured in the NZ. Indeed, for lower values $(50-100 \mathrm{~mm} / \mathrm{min})$, the increase the welding speed has induced an increase of the grain size, consistently with the reduction of the heat input and the inhibition of the grain growth. However, in the upper range (150-200 $\mathrm{mm} / \mathrm{min}$ ), an inversion of this trend, and the progressive reduction of the grain size, has been observed. This can be related to the effect of temperature and effective strain rate on the continuous dynamic recrystallization phenomena, generally resulting in a finer microstructure at relatively higher effective strain rate and lower temperature. Similar considerations can be extended to the graph in Fig. (4b), obviously considering that the temperature field experienced by the processing material is dictated not only by the heat input (due to the tool action) but also by the initial heating. As a consequence, a more pronounced grain growth in the stir zone is reasonably expected.
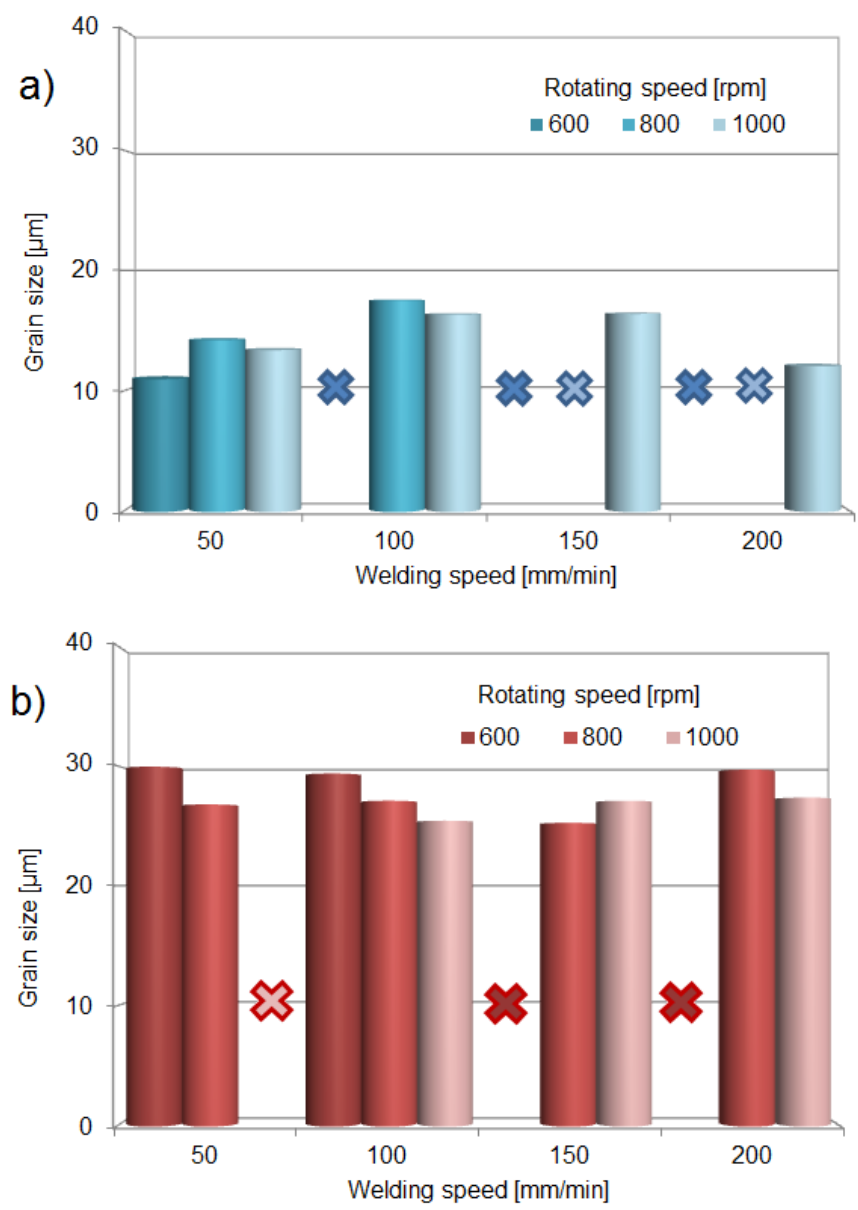

Fig. (4). Measured grain size in the nugget zone of CW (a) and HW (b). The " $\mathrm{x}$ " symbols refer to test cases excluded from the design of experiments.

Microhardness profiles are reported in Fig. (5). In order to improve the readability of the graph, only the HV profiles measured along the test line at half thickness of the cross section are included, taking also into account that no significant through the thickness variation of microhardness has been observed. Obtained data evidence a significant microhardness reduction in all welded samples, with respect to the parent material (about $120 \mathrm{HV}$ ). This trend, already reported in previous researches, has been attributed to a complex annealing effect [11,14,16-19], leading to the reduction of dislocation structures. In the investigate range of the processing parameters, the annealing effect globally 

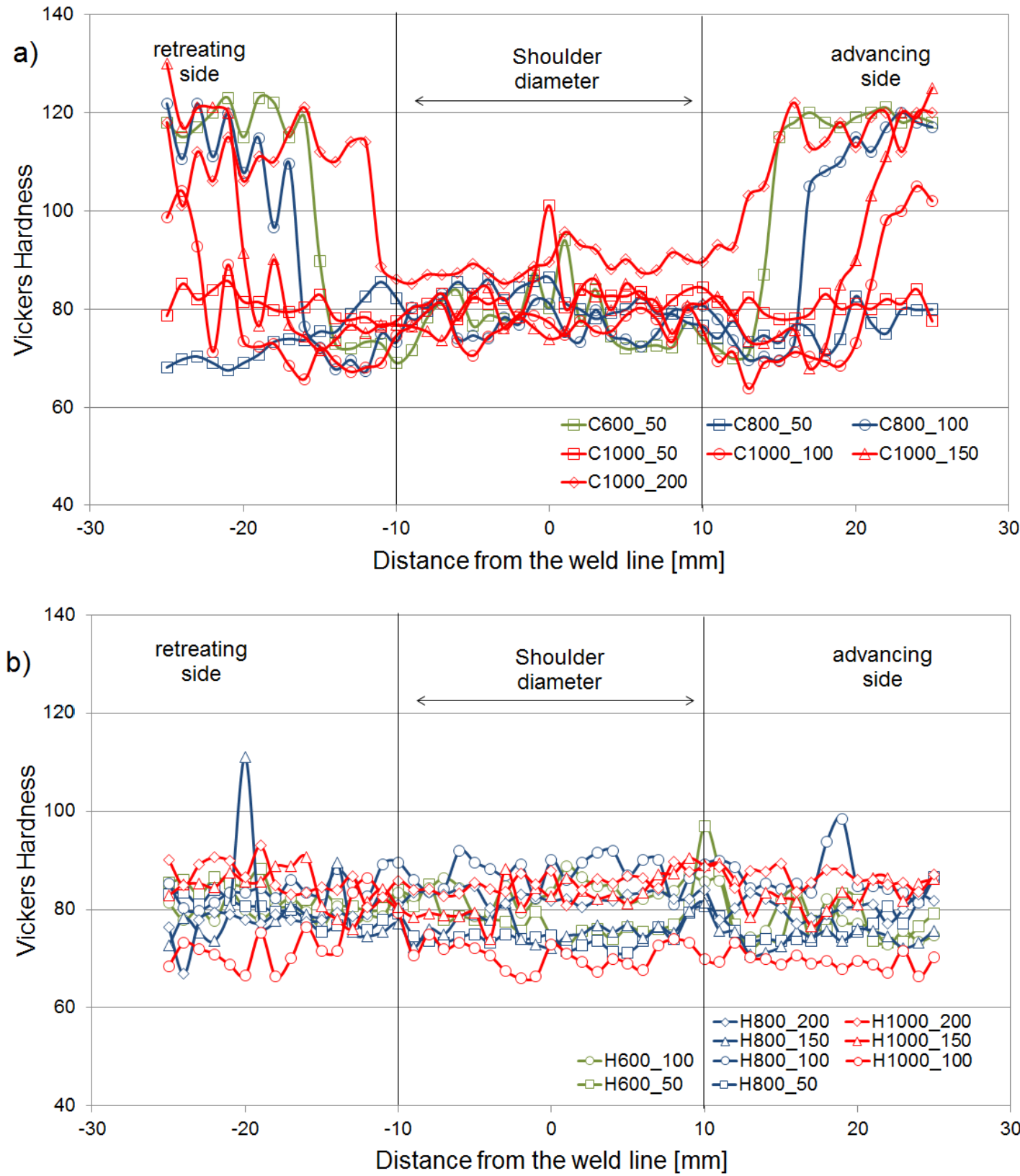

Fig. (5). Microhardness profiles at the half-thickness: CW (a) and HW (b). Line color is representative of the rotating speed, (indicating green, blue, and red colors 600,800 , and $1000 \mathrm{rpm}$, respectively); marker type is associated to the welding speed (being the square, circle, triangle, and diamond representative of $50,100,150,200 \mathrm{~mm} / \mathrm{min})$; each test case is specified using a letter $(\mathrm{C}$ or $\mathrm{H})$ depending on the initial temperature, followed by the rotational speed and finally the welding speed values.

prevails on grain refinement, however, a local effect of microstructure refinement has been observed along the weld line, in particular in CW samples. Regarding CW, the width of the annealed zone strongly depends on the processing parameters, resulting broader at higher welding speed and lower rotational speed. This aspect is easily imputable to heat transfer phenomena. Indeed, increasing the rotational speed the heat generated at material -tool contact surface increases inducing higher temperature; furthermore, at lower $v$ a major amount of material experiences higher temperatures due to conductive heat transfer. The annealing effect has interested the whole section of HW samples. As far as the influence of the process parameters on microhardness profiles is concerned, the obtained outcomes have evidenced that HV increases with the welding speed, while an opposite variation is related to the increase of the rotating speed. Again, this behavior can be correlated to the dependence of the annealing effect on the thermal cycle (mainly relying on $v$ ) and the peak temperature (strongly affected by $\omega$ ). The aforementioned trend has been found in sound as well as defected joints; furthermore the presence of tunnel defects is generally accompanied by lower microhardness values.

Tensile test results are exposed in Fig. (6). An overall reduction of the mechanical properties of the welded material has been found, with respect to the base material, characterized by $137 \mathrm{MPa}$ yield stress, $320 \mathrm{MPa}$ ultimate stress, and $20 \%$ elongation. Considering that in some test cases a tunnel defect has been detected, reducing the 

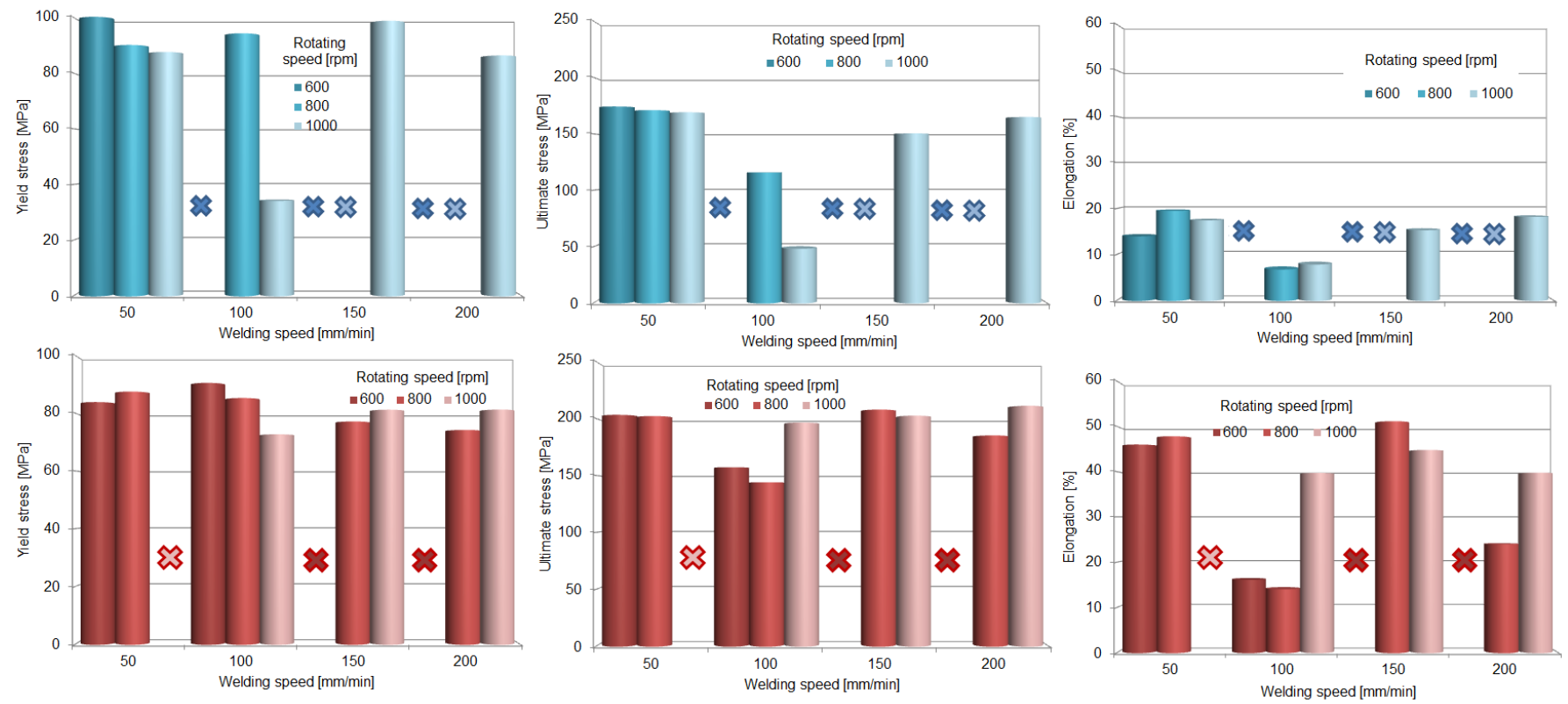

Fig. (6). Yield stress, ultimate stress and elongation: CW (top) and HW (bottom). The " $\mathrm{x}$ " symbols refer to test cases excluded from the design of experiments.

effective cross section of the sample and inducing a stress concentration, a comparative analysis is quite difficult. In general, an increase of the yield stress in $\mathrm{CW}$ conditions with respect to the HW condition is measured. This can be related to the material annealing at relatively higher temperature. On the other hand, lower ultimate stress and the elongation in cold welds have been evaluated with respect to the same parameters provided by how welds, which is well explainable considering the presence of the internal defect.

\section{CONCLUSION}

In this paper results provided by an experimental investigation on C10100 friction stir welding, assuming the butt joint configuration and using and unthreaded conical tool, are reported. In particular, the attention has been focused on the influence of rotating and welding speed, as well as of the processing material initial temperature. The following conclusions can be highlighted:

i. $\quad$ in the explored ranges of process parameters, the used tool geometry is not suitable to establish adequate flow condition without an initial pre-heating. Tunnel defects are detected in all joints realized in $\mathrm{CW}$ condition;

ii. sound joints can be obtained if the welding pitch is lower than $0.15 \mathrm{~mm} / \mathrm{rev}$ and increasing the material initial temperature;

iii. a non-linear dependence of the recrystallized grain size in the NZ with respect to the processing parameters is observed, evidencing the contrasting effect of temperature and strain rate experienced by the material during the process, as well as a significant growth of the newly formed grains;

iv. microhardness profiles are determined by two conflicting effects: annealing (implying the reduction of dislocations density) and grain refinement, which, in turn, strongly rely on the processing parameters; v. an efficiency (ratio between the property of the joined material and of the base material) of approximately $60 \%$ of the joints welded using the pre-heating facility is estimated, relatively to the yield and ultimate stress, while an increase of the elongation at break, imputable to an annealing effect, is measured. The presence of the internal defect drastically penalizes the performance of the cold welded joints.

\section{CONFLICT OF INTEREST}

The authors confirm that this article content has no conflict of interest.

\section{ACKNOWLEDGEMENTS}

Declared none.

\section{REFERENCES}

[1] R.S. Mishra and Z.Y. Ma, "Friction stir welding and processing", Mat. Sci. Eng. R, vol. 50, pp. 1-78, 2005.

[2] H.N.B. Schmidt, T.L. Dickerson, and J.H. Hattel, "Material flow in butt friction stir welds in AA2024-T3", Acta Mater., vol. 54, pp. 1199-209, 2006

[3] M.A. Sutton, B. Yang, A.P. Reynolds, and R. Taylor, "Microstructural studies of friction stir welds in 2024-T3 aluminum", Mat Sci. Eng. A, vol. 323, pp. 160-166, 2002.

[4] B. Yang, J. Yan, M.A. Sutton, and A.P. Reynolds, "Banded microstructure in AA2024-T351 and AA2524-T351aluminum friction stir welds Part I. Metallurgical studies", Mat. Sci. Eng. A, vol. 364, pp. 55-65, 2004.

[5] H.-B.Chen, K. Yan, T. Lin, S.-B.Chen, C.-Y. Jiang, and Zhao Y., "The investigation of typical welding defects for 5456 aluminum alloy friction stir welds", Mat. Sci. Eng. A, vol. 433, pp. 64-69, 2006.

[6] P. Carlone and G.S. Palazzo, "Influence of process parameters on microstructure and mechanical properties in AA2024-T3 friction stir welding", Metallogr. Microstruct. Anal., vol. 2(4), pp. 213-22, 2013.

[7] P. Carlone and G.S. Palazzo, "Longitudinal residual stress analysis in AA2024-T3 friction stir welding", Open Mech. Eng. J., vol. 7 , pp. $18-26,2013$ 
[8] L.-Z. Jin and R. Sandström, "Numerical simulation of residual stresses for friction stir welds in copper canisters", J. Manuf. Process, vol. 14, pp. 71-81, 2012.

[9] L. Cederqvist, O. Garpinger, T. Hägglund, and A. Robertsson, "Cascade control of the friction stir welding process to seal canisters for spent nuclear fuel", Control Eng. Pract., vol. 20, pp. 35-48, Jan, 2012.

[10] M. Jabbari and C.C. Tutum, "Optimum rotation speed for the friction stirwelding of pure copper, ISRN Mater. Sci., vol. 2013, pp. $1-5,2013$.

[11] Y.M. Hwang, P.L. Fan, and C.H. Lin, "Experimental study on friction stir welding of copper metals", J Mater. Process. Tech., vol. 210, pp. 1667-72, 2010

[12] T. Sakthivel and J. Mukhopadhyay,"Microstructure and mechanical properties of friction stir welded copper", J. Mater. Sci., vol. 42, pp. 8126-8129, 2007.

[13] G.M. Xie, Z.Y. Ma, and L. Geng, "Development of a fine-grained microstructure and the properties of a nugget zone in friction stir welded pure copper", Scripta Mater., vol. 57, pp. 73-6, 2007.

[14] Y.F. Sun and H. Fujii, "Investigation of the welding parameter dependent microstructure and mechanical properties of friction stir welded pure copper", Mater. Sci. Eng. A, vol. 527, pp. 6879-6886, 2010 .
[15] J.J. Shen H.J. Liu, and F. Cui, "Effect of welding speed on microstructure and mechanical properties of friction stir welded copper", Mater. Design, vol. 31, pp. 3937-3942, 2010.

[16] P. Xue, G.M. Xie, B.L. Xiao, Z.Y. Ma, and L. Geng, "Effect of heat input conditions on microstructure and mechanical properties of friction-stir-welded pure copper", Metall. Mater. Trans. A, vol. 41, pp. 2010-2021, 2010

[17] H. Khodaverdizadeh, A. Heidarzadeh, and T. Saeid, "Effect of too pin profile on microstructure and mechanical properties of friction stir welded pure copper joints", Mater. Design, vol. 45, pp. 265270, 2013.

[18] W.-B.Lee and S.-B. Jung, "The joint properties of copper by friction stir welding", Mater. Lett., vol. 58, pp. 1041-1046, 2004.

[19] H. Khodaverdizadeh, A. Mahmoudi, A. Heidarzadeh, and E. Nazari, "Effect of friction stir welding (FSW) parameters on strain hardening behavior of pure copper joints", Mater. Design, vol. 35 , pp. 330-334, 2012

[20] P. Xue, B.L. Xiao, Q. Zhang, and Z.Y. Ma, "Achieving friction stir welded pure copper joints with nearly equal strength to the parent metal via additional rapid cooling", Scripta Mater., vol. 64, pp. $1051-1054,2011$.

This is an open access article licensed under the terms of the Creative Commons Attribution Non-Commercial License (http://creativecommons.org/licenses/ by-nc/3.0/) which permits unrestricted, non-commercial use, distribution and reproduction in any medium, provided the work is properly cited. 